Highlighted Article

\title{
Effects of waterborne nano-iron on medaka (Oryzias latipes): Antioxidant enzymatic activity, lipid peroxidation and histopathology
}

\author{
Hongcheng Li, Qunfang Zhou, Yuan Wu, Jianjie Fu, Thanh Wang, Guibin Jiang* \\ State Key Laboratory of Environmental Chemistry and Ecotoxicology, Research Center for Eco-Environmental Sciences, Chinese Academy of Sciences, \\ P.O. Box 2871, Beijing 100085, China
}

\section{A R T I C L E I N F O}

\section{Article history:}

Received 8 November 2007

Received in revised form

11 July 2008

Accepted 1 September 2008

Available online 5 December 2008

\section{Keywords:}

Medaka

Nano-iron

Antioxidant enzyme

Histopathology

Lipid peroxidation

\begin{abstract}
A B S T R A C T
Toxicity tests were performed to investigate possible harmful effects on medaka exposed to nano-iron. Dose-dependent decreases of superoxide dismutase (SOD) and increases of malondialdehyde (MDA) were induced in the medaka embryo, suggesting that oxidative damage was induced by nano-iron. For adult medaka, the disturbance of antioxidative balance was observed during the early exposure period based on the monitoring of the hepatic and cerebral SOD and reduced glutathione (GSH). No terminal oxidative damage occurred during the whole exposure period, probably due to the high self-recovering capability of the adult fish. Some histopathological and morphological alterations (cell swelling, hyperplasia, and granulomas, etc.) were observed in gill and intestine tissues, which confirmed that deleterious effects occurred as a result of direct contact with nano-iron. It is suggested that further evaluation should be made concerning the risk assessment of waterborne nano-iron on aquatic life.
\end{abstract} (c) 2008 Published by Elsevier Inc.

\section{Introduction}

With the increasing presence of nanomaterials in a wide range of commercial products, more and more concerns have been raised regarding their potential toxicity and danger to the environment (Colvin, 2003). Nanomaterials can enter the environment with the disposal of materials containing these hyperfine particles, as well as during the lifetime of "nano-products". Human exposure to nanomaterials mainly occurs as a result of the direct contact to nanomaterial-containing products. Because little is known about the toxicity profile of nanomaterials, no benchmarks or "safe" levels have been set for the concern of human health. Presently, more and more researchers have investigated the toxicological effects and potential environmental impacts of nanomaterials, such as single-walled carbon nanotubes (Cui et al., 2005; Warheit et al., 2004), multi-walled carbon nanotubes (Monteiro-Riviere et al., 2005), fullerenes (Chen et al., 1998; Oberdörster, 2004; Sayes et al., 2005), ultrafine titanium dioxide (Nakagawa et al., 1997; Rahman et al., 2002), quantum dots (Derfus et al., 2004; Green and Howman, 2005), and some transition metals like $\mathrm{Cu}, \mathrm{Au}, \mathrm{Ag}, \mathrm{Zn}$, and their oxides (Goodman et al., 2004; Chen et al., 2006). However, limited available toxicological information on nanomaterials renders people to

\footnotetext{
* Corresponding author. Fax: +861062849179.

E-mail addresses: gbjiang@rcees.ac.cn, gbjiang@mail.rcees.ac.cn (G. Jiang).
}

endure a high risk of using these novel materials, especially in biological and medical applications.

Iron, as a ubiquitous element in the environment, is also an important component in several metalloproteins and plays a crucial role in vital biochemical activities, such as oxygen transport, electron transfer, and catalysis (Aisen et al., 2001). Although iron has miscellaneous biological functions, superfluous iron can pose a threat to organisms. For example, iron overload can induce DNA damage (Mello and Meneghini, 1991) and cause severe diseases like hemochromatosis. Moreover, excessive iron has been shown to be associated with a high risk for carcinogenesis (Huang, 2004).

It is well known that the toxicity of iron is largely based on its ability to catalyze the formation of radicals via the well-known Fenton reaction: catalytic amounts of iron are sufficient to yield hydroxyl radicals $\left(\mathrm{OH}^{-}\right)$from superoxide $\left(\mathrm{O}_{2}^{-}\right)$and hydrogen peroxide $\left(\mathrm{H}_{2} \mathrm{O}_{2}\right)$, jointly known as reactive oxygen intermediates (ROIs). Free radicals are highly reactive species, which can affect antioxidant enzymatic activities, peroxidation of membrane lipids, modification of nucleic acids, and eventually cause cell death and tissue injury. Although there are a number of reports concerning the toxicity of $\mathrm{Fe}^{2+}$ and its oxides (Papanikolaou and Pantopoulos, 2005; Müller et al., 2007), very few studies have been investigated on the toxicity of nano-iron particles so far, especially in aquatic systems. Zero-valent iron, as an effective reducer and catalyzer, was duly noted in the late 1980s. Nowadays, nano-sized iron has been widely used in the remediation process of halogenated organic compounds (Wang and 
Zhang, 1997; Choe et al., 2001; Wei et al., 2004) and other toxic substances (Liao et al., 2003; Kanel et al., 2005; Lien and Wilkin, 2005) in environmental water systems. Accordingly, water exposure routes should be investigated for the potential harmful effects of nano-iron on aquatic ecosystems.

The present study was carried out to estimate the potential effects of nano-iron on the experimental fish (medaka) based on the determination of the antioxidant enzymatic activities, lipid peroxidation and histopathological changes. Both embryos and adult fish were investigated to evaluate the toxicity of nano-iron at different developmental stages of tested species.

\section{Materials and methods}

\subsection{Chemicals and reagents}

Nano-iron particles (average size $30 \mathrm{~nm}$ ) were purchased from the Toda Kogyo Corp (Japan). According to the supplier, nano-iron was modified with a biodegradable polymer (less than $4 \mathrm{wt} \%$ of sodium polyaspartate, which has been acknowledged as non-toxic) to prevent zero-valent iron from being oxidized. Suitable amount of nano-iron powder was diluted by dechlorinated water to make up a series of exposure water $(0,0.5,5,50 \mu \mathrm{g} / \mathrm{mL})$. The nano-iron particles used in our experiments was in general evenly dispersed in the water at the set dosage within one day.

Commercial kits of superoxide dismutase (SOD), malondialdehyde (MDA), and glutahione (GSH) were purchased from Nanjing Jiancheng Bioengineering Institute (NJBI, China).

\subsection{Experimental animal}

A batch of medaka embryos at $48 \mathrm{~h}$ of post-fertilization were chosen as the test subjects.

A batch of 9-month-old adult Japanese medaka with mean length of $3.4 \mathrm{~cm}$ and $0.35 \mathrm{~g}$ in weight were pre-domesticated in a flow-through system. The water quality was controlled as follows: $\mathrm{pH}, 7.0-7.6$; oxygen concentration, $5-7 \mathrm{mg} / \mathrm{L}$; hardness of $\mathrm{CaCO}_{3}, 200 \mathrm{mg} / \mathrm{L}$; conductivity, $650 \mu \mathrm{S} / \mathrm{cm}$; water temperature, $22-25^{\circ} \mathrm{C}$. All fish were fed twice a day with artemia and kept under a 12-h light and $12-\mathrm{h}$ dark cycle.

\subsection{Experimental protocol}

In each group, 50 embryos were administered to a graded series of nano-iron solution $(0,0.5,5,50 \mu \mathrm{g} / \mathrm{mL})$. The exposure solutions were completely changed daily. Embryos were sampled on days $0.5,1.5,2,4,6$, and 8, and the antioxidant enzymatic activities (SOD), lipid peroxidation (MDA) were measured.

Adult medaka fish with 40 fish per group were administered to a graded series of nano-iron $(0,0.5,5,50 \mu \mathrm{g} / \mathrm{mL})$ for consecutive 14 days. All experimental fish were fed twice a day and the exposure water was completely changed daily. Tissues were sampled on days 1, 3, 9, and 14. All the sampled fish from each group were sacrificed in ice-water, dried with filter paper, weighed and finally anatomized for the collection of the target tissues including liver, brain, and intestine. Six liver and brain samples from each group were frozen for the analysis of antioxidant enzymatic activities, lipid peroxidation. Tissues including liver, brain, gill, and intestine were, respectively fixed in $10 \%$ buffered formalin and $5 \%$ glutaraldehyde for subsequent histopathological observation.

\subsection{Analytical procedure}

Stock suspension of nano-iron samples $(1 \mathrm{~mL})$ were weighed and digested with $2 \mathrm{~mL}$ of concentrated nitric acid and $3 \mathrm{~mL}$ of hydrogen peroxide. Iron concentrations were quantified by the combination of microwave-assisted digestion (MAD Mars5 HP500, CEM Corporation, USA) with inductively coupled plasma-mass spectrometry (ICP-MS, Agilent 7500). Prior to each experiment, exposure solutions were diluted in deionized water and quantified using the same method.

All tests of biomarkers were conducted within 2 days after the preparation of tissues. According to results from preliminary experiments, we chose the optimized value of $1: 20(0.86 \% \mathrm{NaCl})$ as the dilution ratio. Embryo, liver, and brain samples were homogenized with ice-cold $0.86 \% \mathrm{NaCl}$ and centrifuged at $12,000 \mathrm{rpm}$ at $4{ }^{\circ} \mathrm{C}$ for $8 \mathrm{~min}$. The resulting supernatants were used for the determination of SOD, MDA, and GSH levels. SOD activity was assayed using the xanthine-xanthine oxidase and nitroblue tetrazolium (NBT) system. One unit of SOD is defined as the amount of protein that inhibits the rate of NBT reduction by $50 \%$ (Sun et al., 1988). MDA levels were assayed using the thiobarbituric acid technique (Ohkawa et al., 1979). GSH levels were determined chemically using 5 , 5-dithionitrobenzoic acid (Ellman, 1959). Protein contents were determined by the Bradford dye-binding assay with bovine serum albumin as standard (Bradford, 1976). The absorbance of SOD, MDA, GSH, and protein were measured at 550, 532, 412, and $590 \mathrm{~nm}$, respectively using a microtiter plate reader (Thermo, Varioskan Flash, USA).

The fixed fish specimen for light microscope was embedded in paraffin blocks after dehydration with a graded ethanol series. The 4-5 $\mu \mathrm{m}$ sections were stained with hematoxylin and eosin ( $\mathrm{H} \& \mathrm{E})$, then observed and photographed under light microscope. For scanning electric microscope (SEM S-3000N, Hitachi, Japan) observation, the fixed and dehydrated specimen was further dehydrated at critical point of $\mathrm{CO}_{2}$ following with the treatment of spray with gold. The accumulation of nano-iron in the intestine tissues was confirmed by scanning electric microscope equipped with energy disperse X-ray spectroscopy (EDS).

\subsection{Statistical analysis}

Data including SOD, GSH, and MDA values are presented as the mean \pm SD. The differences between groups were tested for significance using one-way analysis of variance (ANOVA). Differences were considered significant at $p<0.05$.

\section{Results}

\subsection{Antioxidant enzymatic activities and lipid peroxidation analysis}

To investigate the potential impacts of nano-iron on aquatic organisms, antioxidant enzymatic activities and lipid peroxidation (SOD, GSH, and MDA) were investigated in the exposed embryos and adult medaka at the dose of $0.5,5$, and $50 \mu \mathrm{g} / \mathrm{mL}$. The actual nano-iron concentrations were $0.48 \pm 0.05,4.7 \pm 0.2$, and $46.6 \pm 2.7 \mu \mathrm{g} / \mathrm{mL}$, respectively. Some minor loss of iron was likely due to adherence to the walls of the aquaria.

SOD activities in the embryos after exposure to a series of nano-iron solutions for $12,36 \mathrm{~h}$, and $2,4,6,8$ days are shown in Fig. 1. It was obvious that a general dose-dependent inhibition was induced by nano-iron during the whole exposure period, especially at the high dose of $50 \mu \mathrm{g} / \mathrm{mL}(p<0.01)$. The lowest SOD activity was only approximately at $30 \%$ that of the control. Time-related inhibition of SOD activity was also observed in the embryos during the exposure to $50 \mu \mathrm{g} / \mathrm{mL}$ for 4 days, while no regular changing trend was found in the other exposure groups with the increase of exposure time. Changes of MDA concentration in embryos are shown in Fig. 2. It was found that at the beginning of the exposure, nano-iron induced a slight decrease of MDA due to the response of antioxidant defense system in the embryos. As the exposure prolonged, dose- and time-dependent responses of MDA were observed in groups treated with 5 and $50 \mu \mathrm{g} / \mathrm{mL}$ of nano-iron $(p<0.05)$, which was consistent with the result obtained from the SOD assay above. The MDA contents in

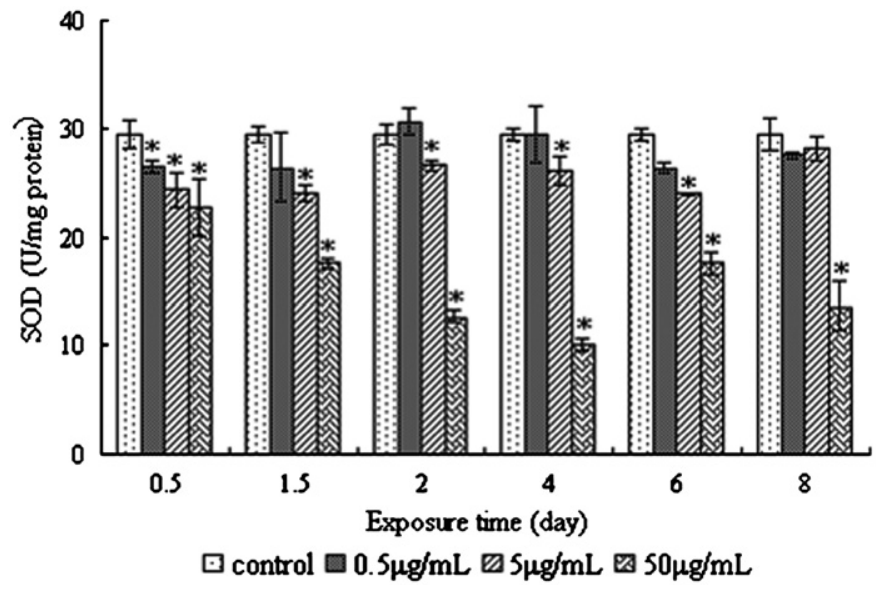

Fig. 1. The changes of SOD activities in medaka embryos exposed to aquatic nanosized iron $\left({ }^{*} p<0.05, n=5\right)$. 
embryos when exposed to $50 \mu \mathrm{g} / \mathrm{mL}$ for 6 and 8 days were 3 -fold higher than that of the controls, indicating serious oxidative damage occurred for embryos as a result of exposure to nano-iron.

SOD, MDA, and GSH levels were measured in liver and brain samples from adult medaka exposed to nano-iron for 1, 3, 9, and

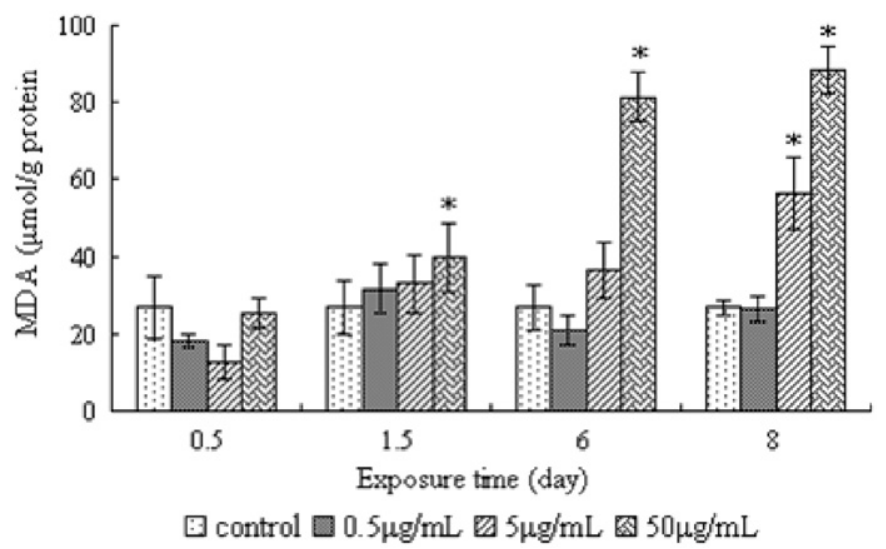

Fig. 2. The changes of MDA contents in medaka embryos exposed to nano-sized iron $\left({ }^{*} p<0.05, n=5\right)$.
14 days, respectively. As shown in Fig. 3, a significant decrease of SOD activity was found in the liver exposed for 1 and 3 days and in the brain exposed for 1 day $(p<0.05)$. However, with the exposure time increased, SOD activities both in liver and brain seemed to be capable of adjusting the antioxidant balance in vivo, possibly due to induction of some endogenous antioxidant enzymes at the gene. GSH assay showed that no significant differences were observed in the liver during the whole exposure period, whereas a dose-dependent decrease was observed in the brain samples exposed for 1 day $(p<0.05)$, but the response disappeared after 3 days of exposure (Fig. 4). With respect to the MDA concentrations (Fig. 5), both liver and brain samples possessed the same levels as the control during the whole exposure, suggesting that no significant production of lipid peroxidation was induced by nano-iron in the adult medaka $(p>0.05)$.

\subsection{Histopathological observations}

Histopathological changes and morphological alterations were examined in slices of the gill and intestine samples from the exposure groups and the control using light microscope and scanning electronic microscope (micrographs of liver and brain are not shown because no significant change was found).

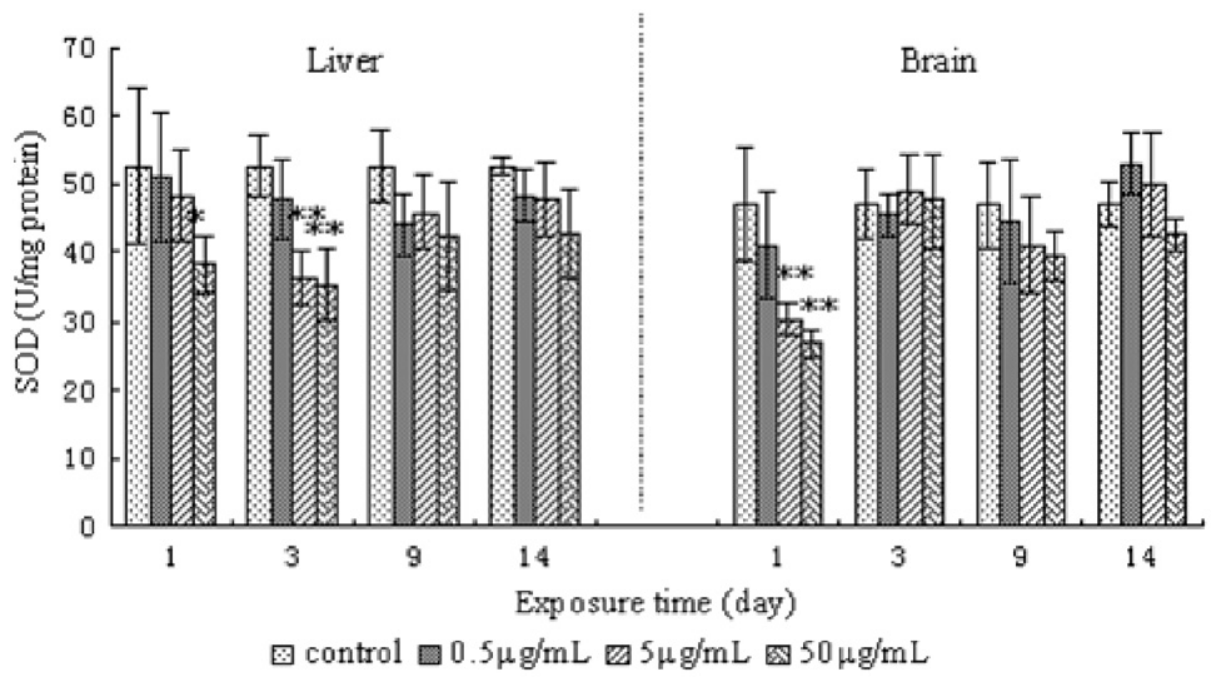

Fig. 3. The changes of SOD activities in the liver and brain of adult medaka exposed to nano-sized iron $\left({ }^{*} p<0.05\right.$ and $\left.{ }^{* *} p<0.01, n=6\right)$.

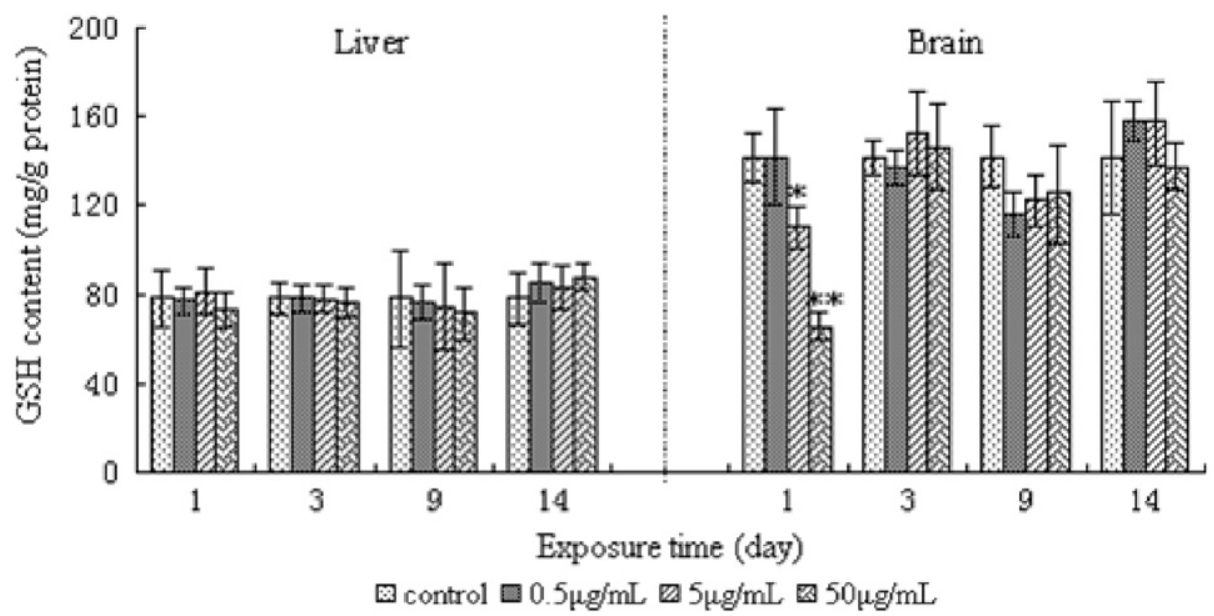

Fig. 4. The changes of GSH contents in the liver and brain of adult medaka exposed to nano-sized iron $\left({ }^{*} p<0.05\right.$ and $\left.{ }^{* *} p<0.01, n=6\right)$. 


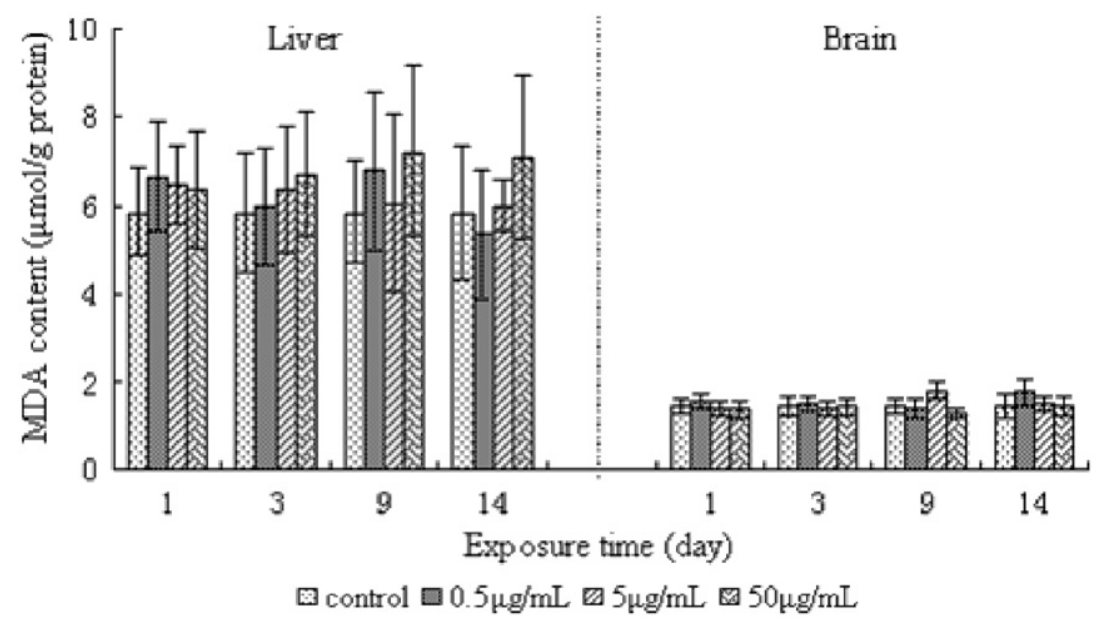

Fig. 5. The changes of MDA contents in the liver and brain of adult medaka exposed to nano-sized iron $(n=6)$.

\subsubsection{Gills}

As shown in Fig. 6A, it could be found that the gill tissue in the control group possessed normal structure with regular array of gill filament and secondary gill lamellae. The squamous epithelium contained pavement cells, chloride cells, and mucous cells. Capillary vessels can be found to a wide extent in the epithelium of the gills with large surface for the effective air and ion exchanges. Similar gill structures was found in the medaka exposed to $0.5 \mu \mathrm{g} / \mathrm{mL}$ of nano-iron, indicating that no obvious damage was induced, while gill tissues exposed to 5 and $50 \mu \mathrm{g} / \mathrm{mL}$ of nano-iron showed distinct histopathological changes. In the gill samples treated with $5 \mu \mathrm{g} / \mathrm{mL}$ of nano-iron (Fig. 6B), the disheveled secondary gill lamellae was covered with swollen epithelium cells and some black particles were deposited on the surface and the regular tactic pillar cells could rarely be found. The gills of the fish exposed to $50 \mu \mathrm{g} / \mathrm{mL}$ of nano-iron displayed more serious injuries such as desquamated structure of gill filament and secondary gill lamellae. As indicated in Fig. 6C, large amount of black iron accumulated on the gills, and a lot of epithelioid granulomas appeared on the secondary gill lamellae. Moreover, the cells were atrophic, resulting in the second gill lamellae becoming more tenuous compared with the control.

The gill tissues including gill filaments, gill arches, and gill rakers were observed using scanning electronic microscope, which also validated the serious morphological changes induced by the exposure of nano-iron. As shown in Fig. 7A, morphology of a normal gill shows tactic strips of gill filaments and second gill lamellae, which offered the respiratory surface and non-respiratory surface and the capillary vessel net was distributed in the respiratory surface of the secondary lamellae. No observable morphological change was found in the gill exposed to $0.5 \mu \mathrm{g} / \mathrm{mL}$ of nano-iron (pictures not shown). However, exposure to $5 \mu \mathrm{g} / \mathrm{mL}$ of nano-iron caused disruption of the gills (Fig. 7B). Parts of the secondary gill lamellae were distorted with breakage on the surface. Furthermore, a large number of particles were found attached to the gills indicating that hypersecretion was initiated by the stimulus from nano-iron exposure. According to the picture shown in Fig. 7C, more serious defeature of the gill was caused by higher dose of nano-iron $(50 \mu \mathrm{g} / \mathrm{mL})$. The structure of respiratory surface and non-respiratory surface on gill filaments and second gill lamellae were almost destroyed, leaving the erose residues with an abundant of small particles. Normal gill arches often have circular microridges covering the surface, which are vital to the fish as they offer large surface for material exchange. Micropits were also spread in the joint of several circular microridges (Fig. 8A). In the low-dose exposure group $(0.5 \mu \mathrm{g} / \mathrm{mL})$, roughly similar arrangement was observed except that the structure seemed to be extruded, resulting in the occurrence of many indentations (Fig. 8B). Obvious swollen phenomena appeared in gill arches from the high-dose exposure groups ( 5 and $50 \mu \mathrm{g} / \mathrm{mL}$ ), leading to the disappearance of most of the circular microridges and close joint between the cells (Fig. 8C and $\mathrm{D}$ ). In the gill rakes, many taste buds are usually covered with regular circular microridges (Fig. 9A), but dose-related swelling of the surface cells occurred with the exposure to nano-iron (Fig. 9B-D). This renders the depth of microridges becoming shallower or even disappearing, wherein the surface of the gill rakers became almost smooth in the exposure group exposed to $50 \mu \mathrm{g} / \mathrm{mL}$ of nano-iron (Fig. 9D).

\subsubsection{Intestines}

Clear and normal intestine tissue can be observed in medaka from the control group (Fig. 10A). The exposure of nano-iron led to varying degrees of accumulation of black particles in the intestines (Fig. 10B-D), which was concluded to be accumulated Fe by EDS (Fig. 11). Moreover, the intestinal villi from the exposed groups became sparse and short, and the intestine wall was comparatively thinner in some parts.

The morphology of the outside surface of the intestine was also investigated by SEM. The control intestine showed distinct intestine epithelium cells with obvious close clearance, and with lots of pores spread throughout the cell membrane (Fig. 12A). Similar to the observations for the other tissues, dose-dependent swelling was also observed from the exposure of $0.5,5$, and 50 $\mu \mathrm{g} / \mathrm{mL}$ of nano-iron. Some cells of intestine wall were noticeably hyperplastic in the low-dose exposure group $(0.5 \mu \mathrm{g} / \mathrm{mL})$ (Fig. 12B). For the group treated by $5 \mu \mathrm{g} / \mathrm{mL}$ of nano-iron, the intestine cells showed more serious swelling, making it difficult to distinguish cell joints in most of the areas (Fig. 12C), and the situation was worsened in the intestines when exposed to $50 \mu \mathrm{g} / \mathrm{mL}$ of nano-iron. The intestine cell surface seemed to be hyperplastic, possibly due to cellular swelling and the loss of close clearance between cells (Fig. 12D).

\section{Discussion}

Manufactured nanoparticles display physicochemical characteristics and coatings that rely on their unique properties. Nano-sized iron has been widely applied in the degradation of 

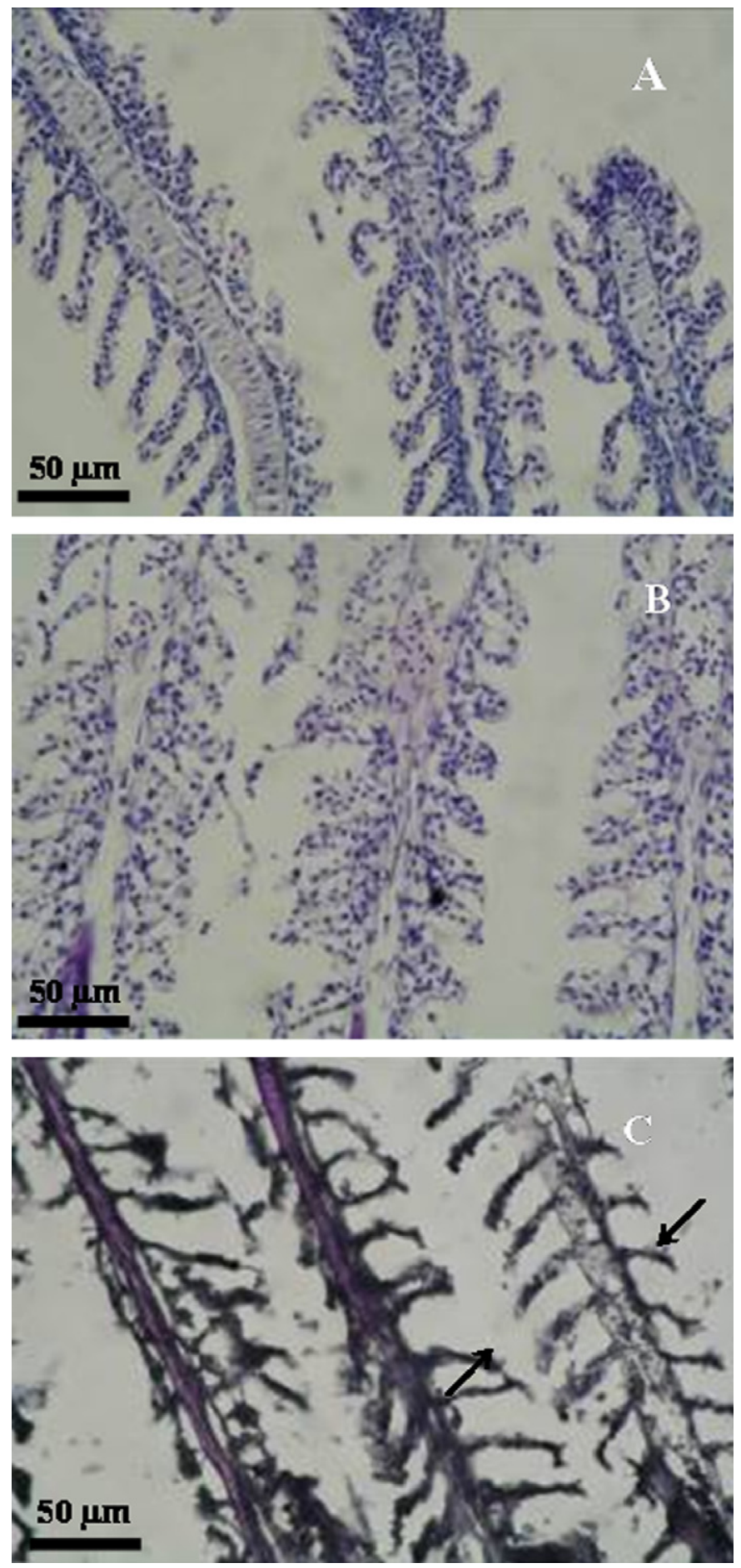

Fig. 6. The histopathological alterations in the gill tissues of adult medaka due to nano-sized iron exposure (A: control, B: $5 \mu \mathrm{g} / \mathrm{mL}$ of nano-iron, and C: $50 \mu \mathrm{g} / \mathrm{mL}$ of nano-iron) [HE, × 200].

halogenated organic compounds and other persistent toxic substances due to its highly effective ability to catalyze redox processes. Nevertheless, this very property may also render nanosized iron hazardous in the environment.

By monitoring several biomarkers including SOD, GSH, and MDA, disturbances of the oxidative defense system caused by the exposure of nano-iron were observed both in embryos and adult medaka. The disturbances were especially prominent during the early exposure period, which proved that aqueous nano-iron
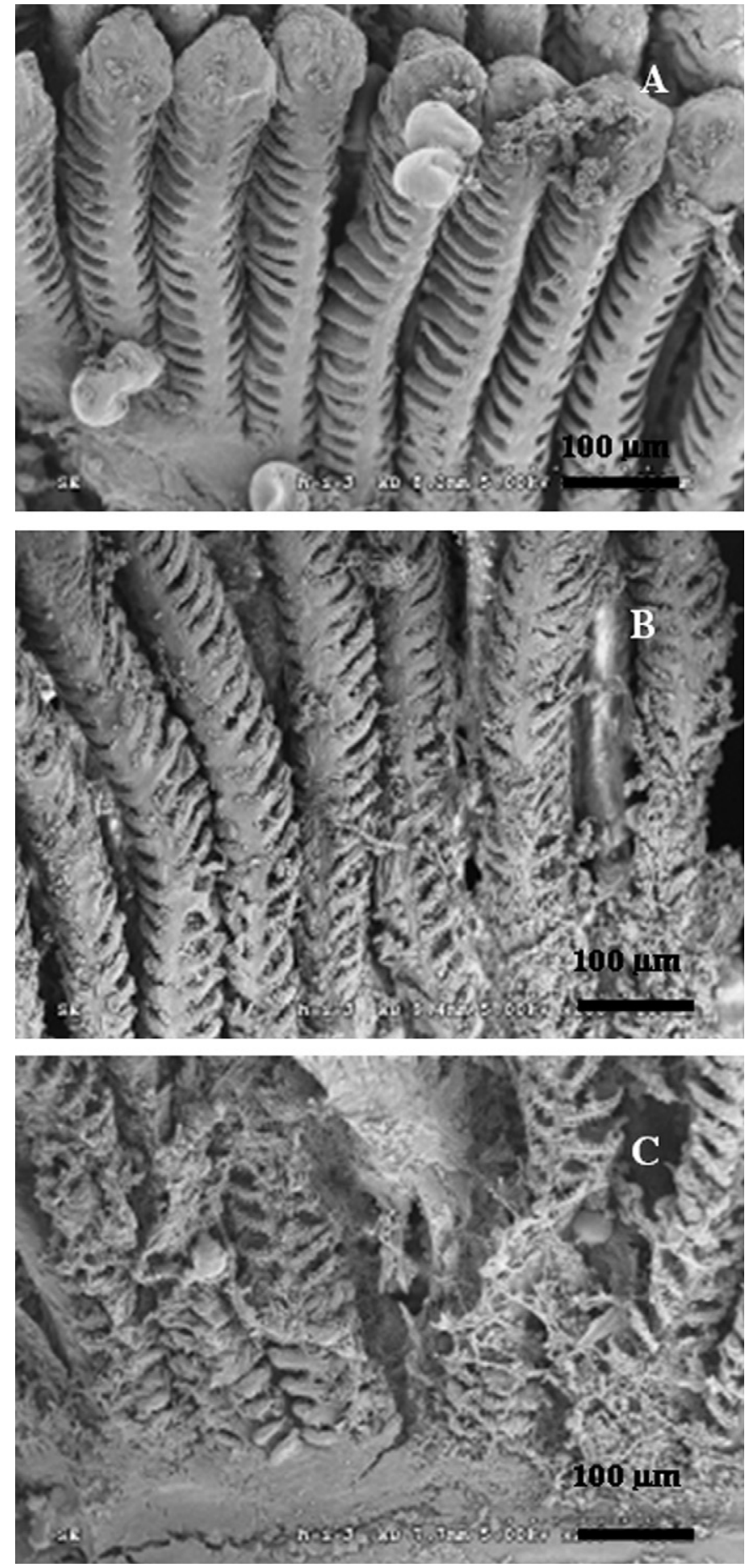

Fig. 7. The morphological alterations in the gill filament of adult medaka due to nano-sized iron exposure (A: control, B: $0.5 \mu \mathrm{g} / \mathrm{mL}$ of nano-iron, C: $5 \mu \mathrm{g} / \mathrm{mL}$ of nano-iron, and $\mathrm{D}: 50 \mu \mathrm{g} / \mathrm{mL}$ of nano-iron).

exposure might promote oxidative stress on medaka by interfering with the antioxidant balance. The toxicity of iron, based on its ability to catalyze the formation of extremely reactive hydroxyl radicals through the Fenton reaction was previously observed, which could cause the depletion or alteration of antioxidants and antioxidant enzymatic activity. Fernaeus and Land (2005) suggested that ScN2a cells were sensitive to iron treatment relating with ROS formation and cell viability, and that ferritin deficiency in infected cells might contribute to iron-induced oxidative stress. 

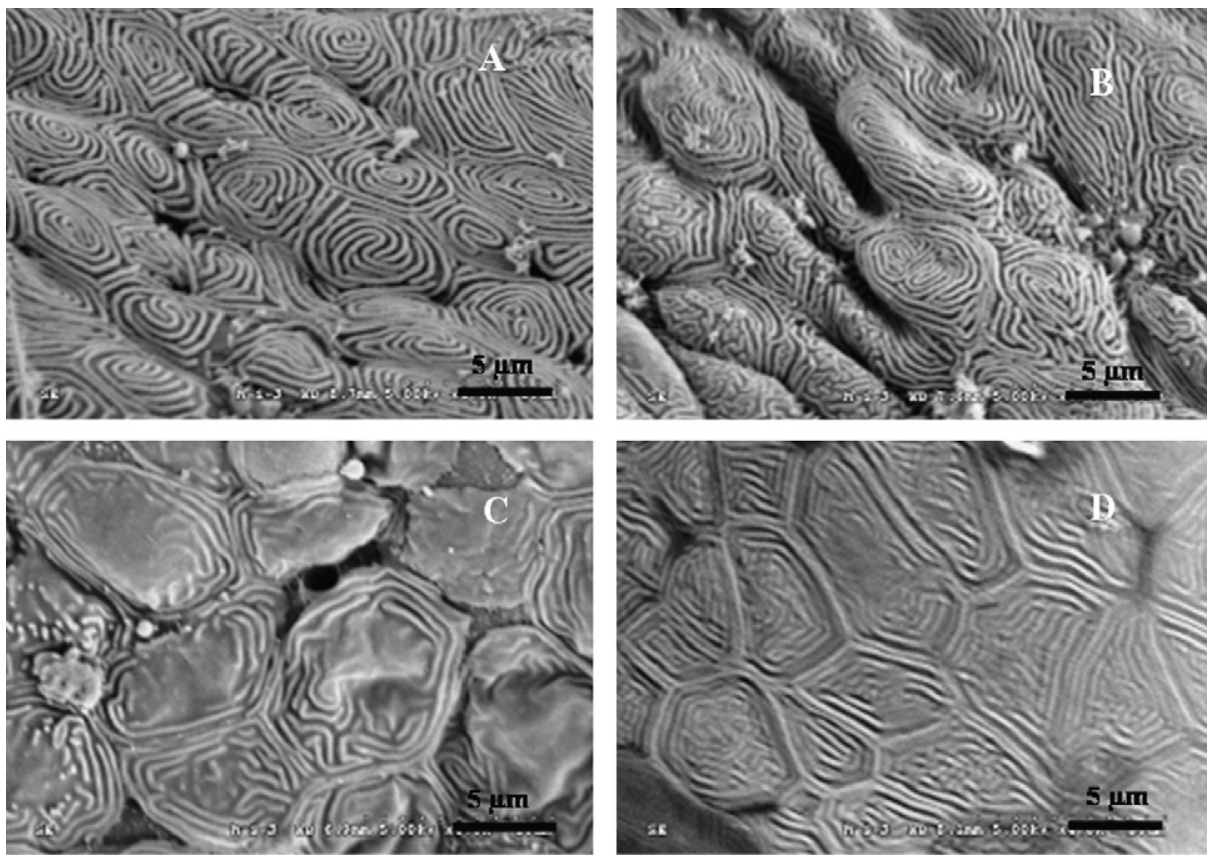

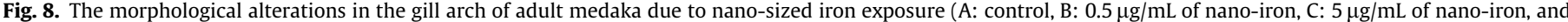
D: $50 \mu \mathrm{g} / \mathrm{mL}$ of nano-iron).
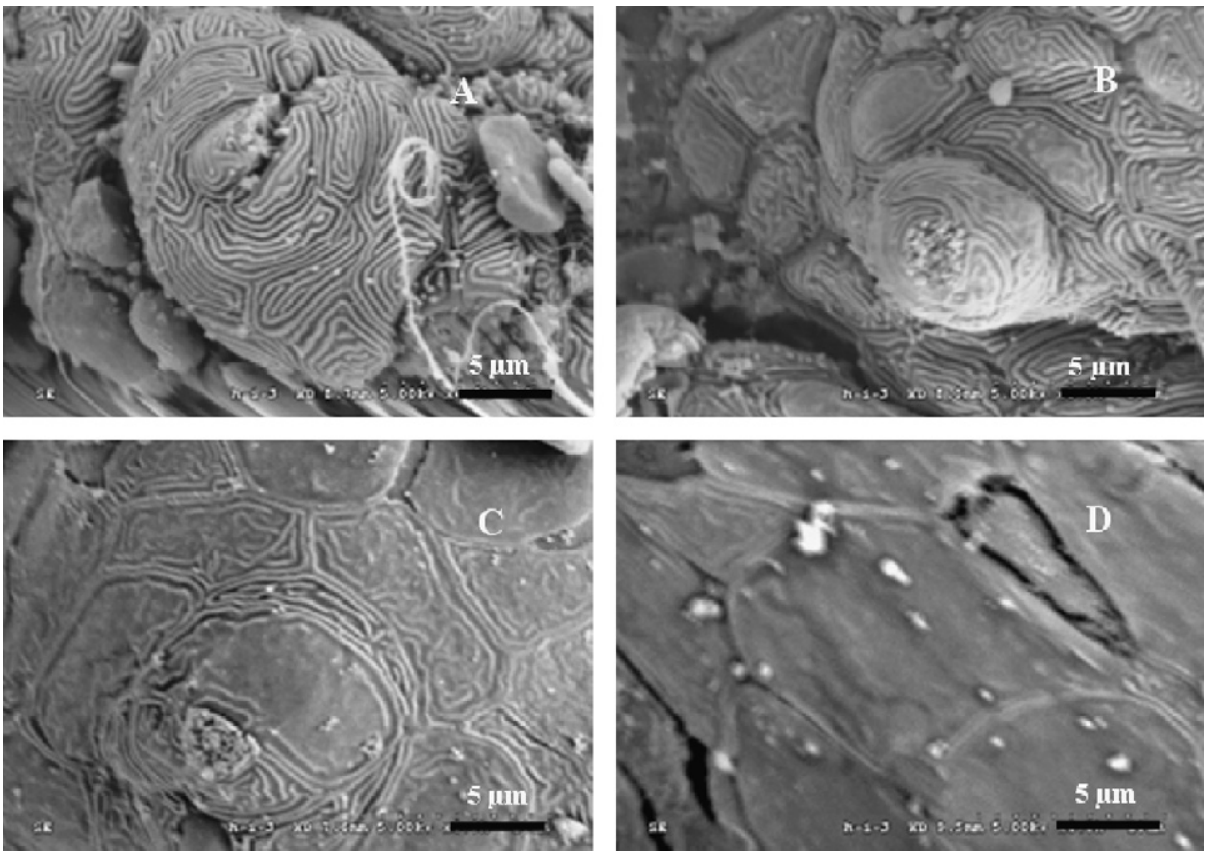

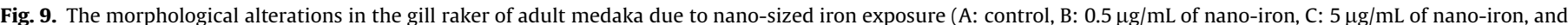
D: $50 \mu \mathrm{g} / \mathrm{mL}$ of nano-iron).

Zhou et al. (2003) concluded that inhalation of ultrafine iron particles $\left(90 \mu \mathrm{g} / \mathrm{m}^{3}\right)$ led to oxidative stress associated with a proinflammatory response in a dose-dependent manner, and the activation of $\mathrm{NF} \kappa \mathrm{B}$ might be involved in iron-induced respiratory responses. The disturbance of antioxidant enzymatic activities and lipid peroxidation were observed in both the embryo and the adult exposed to nano-iron in the present study. In addition, it could be found that the medaka embryo showed to be more sensitive to the exposure of nano-iron than the adults as alteration on levels of SOD, GSH, and MDA led to oxidative damage in the embryos only. While for the adults, hepatic and cerebral SOD activities reduced at the beginning of exposure ( 1 and 3 days) but were restored after 3 days of exposure. Dose-dependent decrease of GSH only occurred in the brain tissue after 1 day of exposure which demonstrated that nano-iron posed impact on the balance of antioxidant defense system in vivo incipiently. However, the medaka fish proved to be able to recover from this initial imbalance and gradually withstood the exterior stress. Thus no 

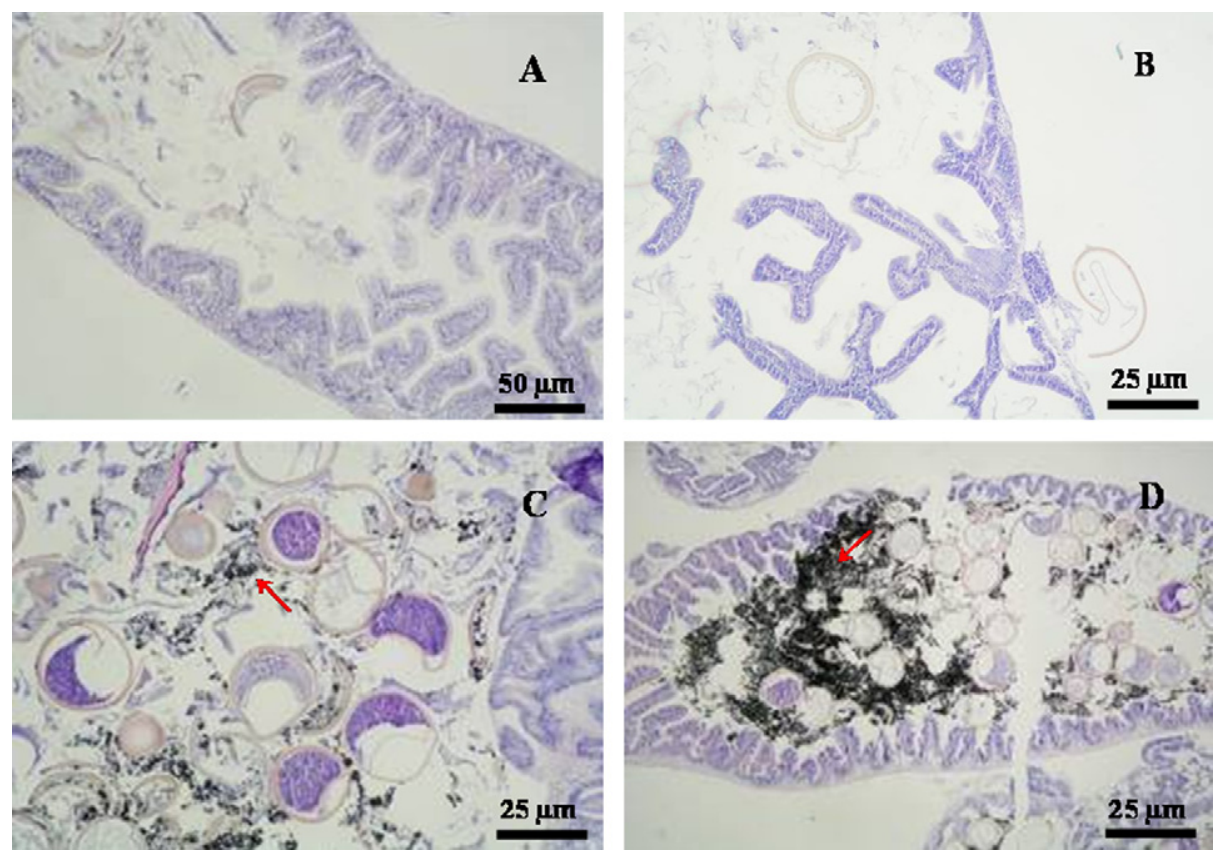

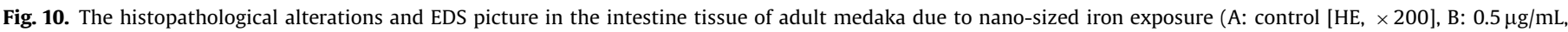
C: $5 \mu \mathrm{g} / \mathrm{mL}$, and D: $50 \mu \mathrm{g} / \mathrm{mL}$ of nano-iron [HE, $\times 400]$ ).

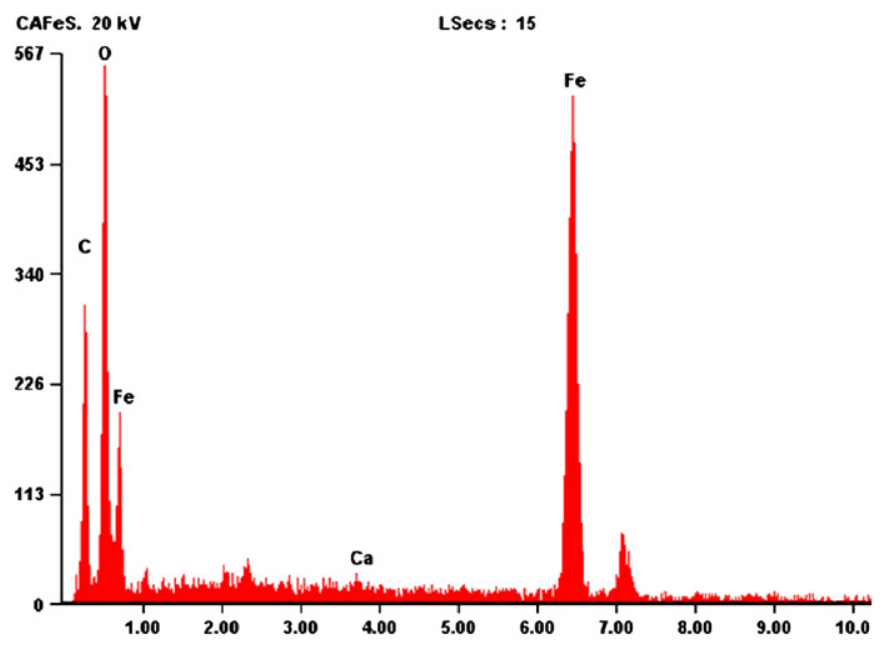

Fig. 11. Accumulation of nano-iron in the intestine tissue of adult medaka confirmed by EDS.

lipid peroxidation appeared in the liver or the brain, indicating no oxidative damage due to nano-iron exposure.

In view of the direct contact of nano-iron particles with gill and intestine tissues, studies were carried out to investigate possible histopathological alterations and morphological changes. Fish gill is a multifunctional organ, which is important for air and ion exchanges, and is composed of gill filament, gill arch, and gill raker. Large amount of capillary vessels are widely distributed in the epithelium of the gill, which is crucial for its functional performance. On the other hand, however, it also serves as the primary tissue for contacting exogenous toxicants in aquatic system. The varying degrees of malformation observed in gill tissues may affect the corresponding functional performance. The swollen epithelium cells in the gill filament, gill arch, and gill raker could reduce the contact surface, thus affecting the air and ion exchange. The breakage occurred on the surface of gill filament and the secondary gill lamellae might provide the direct invasion route for exogenous chemicals. It could be thought that large amounts of nano-iron particles attached on the gill (Fig. 6C) might directly enter into the fish body through the injured epithelial cell, thus inducing the undesirable deleterious and toxic effects. Recent report (Lam et al., 2004) showed that xenogenic carbon nanotubes-induced epithelioid granulomas in lungs of mice and these lesions persisted and were more pronounced after $90 \mathrm{~d}$. Epithelioid granulomas were also observed in the gill tissues from medaka exposed to $50 \mu \mathrm{g} / \mathrm{mL}$ of nano-iron, indicating that similar pathological response might be induced by various nanomaterials in different organisms. Direct exposure through alimentary canal led to the accumulation of nano-iron in intestine tissues as confirmed by EDS (Fig. 11). The swollen epithelial cells on the outside wall of the intestines indicated that incursion and stimulation of accumulated nano-iron particles, which might promote adverse effects on the normal digestion function of medaka and might eventually lead to the corresponding poisoning effects. Further investigation is warranted to more clearly understand the possible action mechanisms of nano-iron in medaka.

\section{Conclusions}

Based on the exposure of the embryo and adult medaka to waterborne nano-iron, we conclude that nano-iron could inhibit SOD activity and induce MDA production in medaka embryos during the whole exposure process. For adult medaka, the hepatic and cerebral antioxidant balances were disrupted by nano-iron in the beginning of exposure, but could be gradually reequilibrated with the exposure time. Histopathological and morphological observations indicated that the deleterious changes may directly or indirectly affect the corresponding functional performances. Since previous studies show that toxicity of nanoparticles can largely vary between different species and suggest that the evaluation of nanotoxicology should be carried out on a case by case basis, more studies are needed to 

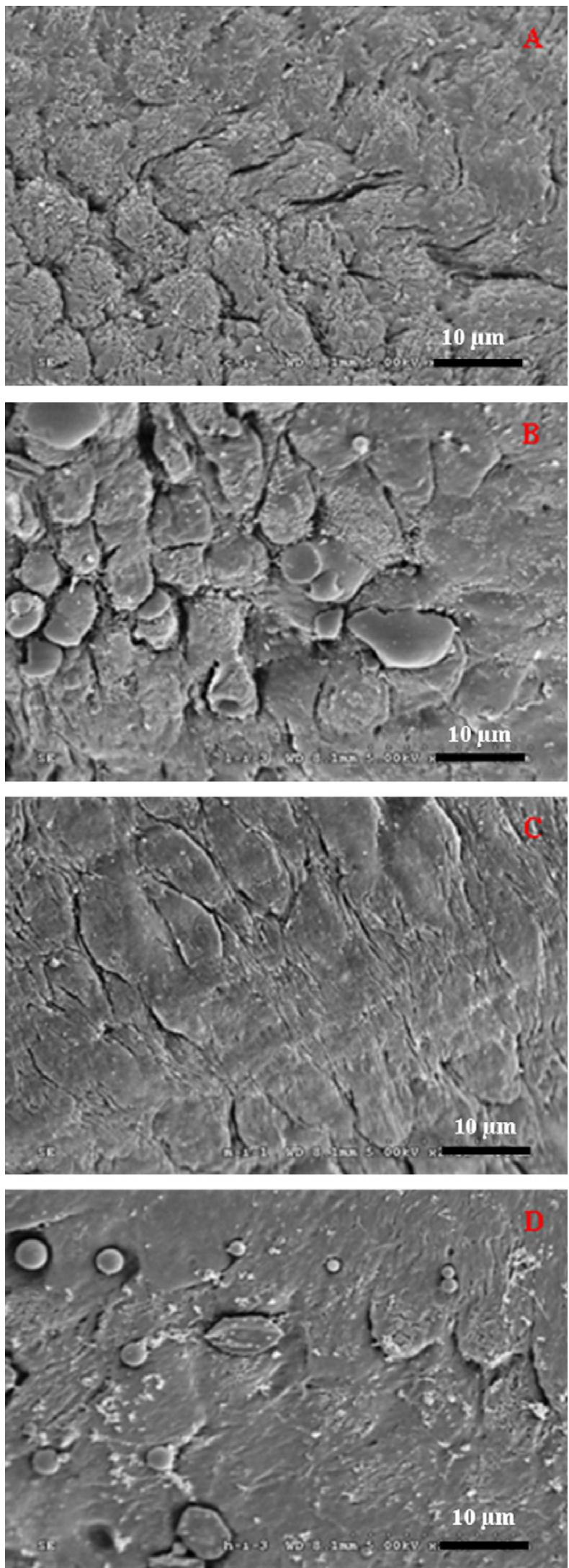

Fig. 12. The morphological alterations in the outside wall of adult medaka intestine due to nano-sized iron exposure (A: control, B: $0.5 \mu \mathrm{g} / \mathrm{mL}$ of nano-iron, C: $5 \mu \mathrm{g} / \mathrm{mL}$ of nano-iron, and D: $50 \mu \mathrm{g} / \mathrm{mL}$ of nano-iron). evaluate the possible biological effects of nano-iron on aquatic ecosystems.

\section{Acknowledgments}

This work was jointly supported by the National Natural Science Foundation of China (20537020), Chinese Academy of Sciences (KZCX2-YW-420-21) and Beijing Nova Programme (2004A51).

\section{References}

Aisen, P., Enns, C., Wessling-Resnick, M., 2001. Chemistry and biology of eukaryotic iron metabolism. Int. J. Biochem. Cell Biol. 33, 940-959.

Bradford, M., 1976. A rapid and sensitive method for the quantification of microgram quantities of protein utilizing the principle of protein-dye binding. Anal. Biochem. 72, 248-254.

Chen, H.H., Yu, C., Ueng, T.H., Chen, S., Chen, B.J., Huang, K.J., Chiang, L.Y., 1998. Acute and subacute toxicity study of water-soluble polyalkylsulfonated C60 in rats. Toxicol. Pathol. 26, 143-151.

Chen, Z., Meng, H., Xing, G.M., Chen, C.Y., Zhao, Y.L., Jia, G., Wang, T.C., Yuan, H., Ye, C., Zhao, F., Chai, Z.F., Zhu, C.F., Fang, X.H., Ma, B.C., Wan, L.J., 2006. Acute toxicological effects of copper nanoparticles in vivo. Toxicol. Lett. 163, 109-120.

Choe, S., Lee, S.H., Chang, Y.Y., Hwang, K.Y., Khim, J., 2001. Rapid reductive destruction of hazardous organic compounds by nanoscale $\mathrm{Fe}^{0}$. Chemosphere 42, 367-372.

Cui, D.X., Tian, F.R., Ozkan, C.S., Wang, M., Gao, H.J., 2005. Effect of single wall carbon nanotubes on human HEK293 cells. Toxicol. Lett. 155, 73-85.

Colvin, V.L., 2003. The potential environmental impact of engineered nanomaterials. Nat. Biotechnol. 21, 1166-1170.

Derfus, A., Chan, W., Bhatia, S., 2004. Probing the cytotoxicity of semiconductor quantum dots. Nano Lett. 4, 11-18.

Ellman, G.L., 1959. Tissue sulfhydryl groups. Arch. Biochem. Biophys. 82, 70-77.

Fernaeus, S., Land, T., 2005. Increased iron-induced oxidative stress and toxicity in scrapie-infected neuroblastoma cells. Neurosci. Lett. 382, 217-220.

Goodman, C.M., McCusker, C.D., Yilmaz, T., Rotello, V.M., 2004. Toxicity of gold nanoparticles functionalized with cationic and anionic side chains. Bioconjugate Chem. 15, 897-900.

Green, M., Howman, E., 2005. Semiconductor quantum dots and free radical induced DNA nicking. Chem. Commun. 1, 121-123.

Huang, X., 2004. Iron overload as a risk factor and molecular mechanism of carcinogenesis. Environ. Mol. Mutagen. 44, 206, 81A.

Kanel, S.R., Manning, B., Charlet, L., Choi, H., 2005. Removal of arsenic(III) from groundwater by nanoscale zero-valent iron. Environ. Sci. Technol. 39, 1291-1298.

Lam, C.W., James, J.T., McCluskey, R., Hunter, R.L., 2004. Pulmonary toxicity of single-wall carbon nanotubes in mice 7 and 90 days after intratra-cheal instillation. Toxicol. Sci. 77, 126-134.

Liao, C.H., Kang, S.F., Hsu, Y.W., 2003. Zero-valent iron reduction of nitrate in the presence of ultraviolet light, organic matter and hydrogen peroxide. Water Res. 37, 4109-4118.

Lien, H.L., Wilkin, R.T., 2005. High-level arsenite removal from groundwater by zero-valent iron. Chemosphere 59, 377-386.

Mello, A.C., Meneghini, R., 1991. Iron is the intracellular metal involved in the production of DNA damage by oxygen radicals. Mutat. Res. Rev. Mutat. Res. 251, 109-113.

Müller, K., Skepper, J.N., Posfai, M., Trivedi, R., Howarth, S., Corot, C., Lancelot, E., Thompson, P.W., Brown, A.P., Gillard, J.H., 2007. Effect of ultrasmall superparamagnetic iron oxide nanoparticles (Ferumoxtran-10) on human monocyte-macrophages in vitro. Biomaterials 28, 1629-1642.

Nakagawa, Y., Wakuri, S., Sakamoto, K., Tanaka, N., 1997. The photogenotoxicity of titanium dioxide particles. Mutat. Res. Rev. Mutat. Res. 394, 125-132.

Monteiro-Riviere, N.A., Nemanich, R.J., Inman, A.O., Wang, Y.Y.Y., Riviere, J.E., 2005 Multi-walled carbon nanotube interactions with human epidermal keratinocytes. Toxicol. Lett. 155, 377-384.

Oberdörster, E., 2004. Manufactured nanomaterials (fullerenes, C60) induce oxidative stress in the brain of juvenile Largemouth Bass. Environ. Health Perspect. 112, 1058-1062.

Ohkawa, H., Ohishi, N., Yagi, K., 1979. Assay for lipid peroxides in animal tissues by thiobarbituric acid reaction. Anal. Biochem. 95, 351-358.

Papanikolaou, G., Pantopoulos, K., 2005. Iron metabolism and toxicity. Toxicol. Appl. Pharmacol. 202, 199-211.

Rahman, Q., Lohani, M., Dopp, E., Pemsel, H., Jonas, L., Weiss, D.G., Schiffmann, D. 2002. Evidence that ultrafine titanium dioxide induces micronuclei and apoptosis in syrian hamster embryo fibroblasts. Environ. Health Perspect. 110, 797-800.

Sayes, C.M., Gobin, A.M., Ausman, K.D., Mendez, J., West, J.L., Colvin, V.L., 2005. Nano-C60 cytotoxicity is due to lipid peroxidation. Biomaterials 26, 7587-7595.

Sun, Y., Larry, W., Oberley, W., Ying, L., 1988. A simple method for clinical assay of superoxide dismutase. Clin. Chem. 34, 497-500. 
Wang, C.B., Zhang, W.X., 1997. Synthesizing nanoscale iron particles for rapid and complete dechlorination of TCE and PCBs. Environ. Sci. Technol. 31, 2154-2156.

Warheit, D.B., Laurence, B.R., Reed, K.L., Roach, D.H., Reynolds, G.A.M., Webb, T.R. 2004. Comparative pulmonary toxicity assessment of single-wall carbon nanotubes in rats. Toxicol. Sci. 77, 117-125.
Wei, J.J., Xu, X.H., Wang, D.H., 2004. Catalytic dechlorination of 0 -chlorophenol by nanoscale Pd/Fe. J. Environ. Sci. 16, 621-623.

Zhou, Y.M., Zhong, C.Y., Kennedy, I.M., Pinkerton, K.E., 2003. Pulmonary responses of acute exposure to ultrafine iron particles in healthy adult rats. Environ. Toxicol. 18, 227-235. 